This file was dowloaded from the institutional repository Brage NIH - brage.bibsys.no/nih

Kolnes, L.-J., Stensrud, T. (2018). Exercise-induced laryngeal obstruction in athletes: Contributory factors and treatment implications. Physiotherapy Theory and Practice, under utgivelse. doi:10.1080/09593985.2018.1474306

Dette er siste tekst-versjon av artikkelen, og den kan inneholde små forskjeller fra forlagets pdf-versjon. Forlagets pdf-versjon finner du her:

http://dx.doi.org/10.1080/09593985.2018.1474306

This is the final text version of the article, and it may contain minor differences from the journal's pdf version. The original publication is available here: http://dx.doi.org/10.1080/09593985.2018.1474306 


\section{Exercise-induced laryngeal obstruction in athletes: contributory factors and treatment implications}

\section{INTRODUCTION}

In recent years, a number of otherwise healthy adolescent athletes competing at regional to national level in their respective sports have been referred to pulmonary physicians, paediatricians as well as to physical therapists for respiratory difficulties. The athletes typically present with exercise-related respiratory symptoms including dyspnoea, cough, inspiratory wheeze and tightness in the throat. Due to severe problems with inhalation during high-intensity exercise (e.g., intervals, competitions), the athletes are frequently forced to interrupt their activity. They report that their breathing problems usually recede within a few minutes of having done so. Most of these athletes do not show bronchial obstruction when performing bronchial provocation tests such as exercise or methacholine challenges, thus an asthma diagnosis may be excluded. In addition, despite no evidence to support the diagnosis of asthma, a number of athletes have received asthma medication without any effect. The presenting clinical symptoms are consistent with exercise-induced laryngeal obstruction (EILO), a phenomenon in which closure of the larynx occurs during high-intensity exercise. This cause of breathing difficulty is frequently undetected, as its aetiology is not yet fully explicated or understood.

The lack of treatment options for athletes with such symptoms, and the uncertainty and distress the symptoms can cause for the athletes and their parents, led to a group of athletes being advised to try a physical therapy approach with a long tradition of altering the breathing pattern. ${ }^{1}$ The physical therapy examination showed increased bodily tension, moderate postural de-alignments and a thoracic or upper chest breathing pattern. The main respiratory movement was typically in the upward direction, instead of abdominal or downward. The assessment revealed increased tension in respiratory muscles, but also in muscles in other parts of the body. Treatment followed the main principles of the NPMP approach, as well as elements of cognitive-behavioural therapy. Various massage techniques

\footnotetext{
${ }^{1}$ The physical therapy was conducted by the first author, a specialist in Norwegian psychomotor physiotherapy (NPMP). In NPMP, the body is considered a functional entity and respiration is assigned significant meaning; it not only mirrors emotional states in the person, but also has a key role in maintaining optimal posture and balanced tension in muscles of the whole body. Treatment aims to normalize posture and dysfunctional breathing patterns.
} 
and exercises were also used, with the aim of releasing tension in respiratory muscles, facilitating change of the respiratory pattern towards more abdominal respiration and promoting normalization of postural de-alignments (in particular of the cervical spine).

The consultations involved verbal reflection about how to adapt the training schedule to avoid triggering the inspiratory symptoms. Exercises and intervals with low or moderate intensity were recommended in place of intervals with high intensities, particularly during the first phase of the intervention. It was assumed that the experience of accomplishing the exercise or competition would provide feelings of coping, as opposed to a sense of failure associated with discontinuation, and the athletes confirmed this to be the case. Intensity could gradually increase during training, without provoking inspiratory symptoms. Importantly, as levels of daily life stress are relatively high in these athletes, and since they are also concerned about their performance at school, the prospect of changing the pace and priorities of everyday life was explored. During the first $3-4$ weeks, the clients had physical therapy sessions once a week, and then later every two weeks to once a month. Nearly all clients reported a reduction of symptoms after $3-4$ weeks of treatment; their inspiratory obstructions became less severe and they could gradually tolerate a higher training intensity without invoking respiratory difficulties, compared to before they started physical therapy.

It appears timely to ask what it was about this intervention that helped lessen the inspiratory obstruction in the clients. It could be hypothesized that the initial upper chest breathing pattern and associated tension in respiratory muscles, as well as the cervical de-alignments observed in some of the clients, contributed considerably to their inspiratory problems. If so, facilitating a more balanced tension in respiratory muscles and enabling a diaphragmatic breathing pattern, in combination with clients avoiding the intense physical activity that triggers the obstruction, may have contributed to the improvement. In the case of upper chest breathing, respiratory muscles (including the pectorals, scalene, sternocleidomastoid, trapezius and upper intercostal muscles) compensate for the lack of abdominal breathing and downward movement of the diaphragm and lateral movements of the ribs. They do this by elevating and stabilizing the upper thorax and shoulders in order to enable expansion 
of the trunk in the vertical direction. Consequently, these muscles become increasingly tense, and, if this becomes a pattern, a compensatory postural adaptation may occur, involving a forward head posture and protraction of the shoulders, as observed in clients with exercise-related respiratory

difficulties (Kolnes, 2016b). Muscles directly or indirectly connected to the larynx are inevitably also part of the respiratory system, therefore a dysfunctional breathing pattern may induce conflicting forces and sensitization at the laryngeal level, as discussed in more detail later in this article.

These observations have triggered interest in further exploring the phenomenon of exerciseinduced laryngeal obstruction. A more comprehensive understanding of contributing mechanisms is essential for creating appropriate treatment procedures for athletes with EILO, given the potential implications for health and performance if EILO remains untreated. Also, appropriate treatment alternatives are imperative in this context given the strict regulations regarding the use of medications. Informed by knowledge from physical therapy, voice rehabilitation and singing - the latter two essentially concerned with the function of laryngeal structures and with features influencing the quality of voice - this theoretical article explores bodily mechanisms and structures that may disturb laryngeal function during strenuous exercise. Firstly, the current situation with respect to EILO diagnosis, its aetiology and treatment options are presented. Secondly, considerations associated with laryngeal structures, muscles and position, and their potential influence on laryngeal function, movement and sensitivity, are examined. Thirdly, the manner in which postural de-alignment (in particular of the cervical spine) and the breathing pattern may interfere with laryngeal functioning will be discussed. Finally, some interventions for voice disorders and singing and the relevance of these for the managing of EILO are evaluated.

\section{CURRENT SITUATION IN EILO - DIAGNOSIS, AETIOLOGY AND TREATMENT}

The experience of inspiratory obstruction of the larynx during exercise is not unusual in healthy individuals, with prevalence in the general adolescent population and in athletes estimated to be $7 \%$ (Christensen, Thomsen, Rasmussen, \& Backer, 2011; Johansson et al., 2015) and 35\% (Nielsen, 
Hull, \& Backer, 2013), respectively. While the laryngeal tract opens to allow for increased airflow during exercise, a reduction of the lumen occurs in cases of laryngeal obstruction. In recent years, the term 'exercise-induced laryngeal obstruction' (EILO) has been applied to describe exercise-related abnormal tightening of the laryngeal tract, especially during inhalation (Liyanagedara, McLeod, \& Elhassan, 2016; Røksund, Heimdal, Clemm, Vollsæter, \& Halvorsen, 2016). While EILO appears to resemble vocal cord dysfunction (VCD) and paradoxical vocal fold motion (PVFM), it is in fact different from VCD and PVFM in that the narrowing is either caused by a reduction at the glottic level (i.e. by adduction of the vocal folds) or the supraglottic level (i.e. by movements of the epiglottis or the aryepiglottic folds), or a narrowing at both levels (Olin et al., 2015; Røksund et al., 2016). Also, incidents of EILO are essentially connected with breathing problems during highintensity exercise, whereas VCD and PVFM are not exercise-related phenomena.

Dyspnoea is the predominant symptom reported during EILO episodes, followed by wheezing, stridor and cough, tightness in the chest and/or throat, and voice changes (Liyanagedara et al., 2016; Morris \& Christopher, 2010). The symptoms typically recede after a short period of rest (Al-Alwan \& Kaminsky, 2012; Olin et al., 2015). Clinical symptoms of respiratory distress and dyspnoea, the presence of abnormal flow volume loops (FVL) confirmed via pulmonary function testing, and visualization of the laryngeal tract during symptoms, are the main criteria for establishing the diagnosis of EILO (Christensen, Thomsen, Rasmussen, \& Backer, 2010; Heimdal, Roksund, Halvorsen, Skadberg, \& Olofsson, 2006; Maat et al., 2009; Roksund et al., 2009; Tervonen et al., 2009). Laryngoscopic visualization of inappropriate glottic or supraglottic movement causing the narrowing is considered essential for making the EILO diagnosis. A continuous laryngoscopy exercise (CLE) test providing key information on the degree of obstruction has been developed for this purpose (Heimdal et al., 2006; Maat et al., 2009), although the test does not appear to be a robust means for reliably classifying the severity of EILO (Walsted, Hull, Hvedstrup, Maat, \& Backer, 2017). Unfortunately, the clinical presentation of EILO is often misdiagnosed and patients receive medical treatment for asthma, exercise-induced bronchoconstriction or exercise-induced asthma, 
despite lack of evidence to support the diagnoses and continued lack of response to such treatment (McFadden Jr \& Zawadski, 1996; McQuaid, Spieth, \& Spirito, 1997; Newman, Mason, \& Schmaling, 1995; Nielsen et al., 2013; Thomas, Geddes, \& Barnes, 1999).

In the absence of organic pathology, various theories have been introduced to explain the aetiology of EILO, such as hypersensitivity, structural origins, psychological causes and increased activation of the autonomic nervous system. Symptoms of EILO seem overrepresented among swimmers and athletes in winter sports and ball games with activity characterized by high-intensity intervals (Rundell \& Weiss, 2013). Since the larynx is richly innervated, repeated exposure to irritants, such as extremely cold air, is assumed to cause laryngeal hypersensitivity and adduction at the glottic level (Ayres \& Mansur, 2011; Benninger, Parsons, \& Mastronarde, 2011). It is hypothesized that disturbed interaction between reflexes and structures at the laryngeal level may trigger constriction of the larynx (Perkner et al., 1998). It is also suggested that the observation of symptoms debuting during puberty may be related to the reduced size of laryngeal structures in young people compared to adults (Hocevar-Boltezar, Krivec, \& Sereg-Bahar, 2017; Wysocki, Kielska, Orszulak, \& Reymond, 2008). Significant gender differences in the laryngeal opening after puberty have been identified (Castelli, Ramirez, \& Nasjleti, 1973), and may explain why laryngeal obstruction exists more often in girls than in boys post puberty (Morris \& Christopher, 2010). It has been suggested that psychological factors, including anxiety, depression, personality disorders and post-traumatic stress contribute to laryngeal obstruction (Powell et al., 2007). Thus, this population is in general highly functioning and psychologically healthy, but reports situational-related stress caused by repeated experiences of airway obstruction and lack of an appropriate diagnosis (Benninger et al., 2011; Boulet, 2012; Newsham, Klaben, Miller, \& Saunders, 2002; RichardsMauze \& Banez, 2014; Roksund, Heimdal, Olofsson, Maat, \& Halvorsen, 2015). Emotional factors may therefore be secondary to the dyspnoea and related to uncertainty over the diagnosis, as well as the associated lack of control over the situation. 
Respiration is in part regulated by the autonomic nervous system (ANS). With the exception of skeletal muscles and the skeleton, the ANS is involved in regulation of nearly all internal organs (e.g., blood vessels, heart and lungs). It acts in response to information from the body and the surroundings to either stimulate (sympathetic ANS) or reduce bodily processes (parasympathetic ANS). Activation of the ANS is linked to psychological and physical stressors (Gilbert, 2003, 2014). Psychological stressors (e.g. excitement or nervousness about performing) trigger the ANS, and this may influence respiration in multiple ways, such as altered respiratory rate and expiratory time (Masaoka \& Homma, 1997, 2001; Wilhelm, Gevirtz, \& Roth, 2001), or laryngeal obstruction and hyperactivity (Ayres \& Gabbott, 2002). It is possible that this laryngeal hyper-responsiveness may lead to laryngeal dysfunction, and that stimuli triggered by emotional stressors or temperature changes induce parasympathetic reflexes causing laryngeal narrowing (Ayres \& Gabbott, 2002; Idrees \& Fitzgerald, 2015).

A number of interventions regularly applied in the managing of VCD, including speech therapy (Christopher \& Morris, 2010; Mathers-Schmidt, 2001; Newsham et al., 2002; Sullivan, Heywood, \& Beukelman, 2001), cognitive behavioural therapy (Richards-Mauze \& Banez, 2014), and psychotherapy (McQuaid et al., 1997; Olin et al., 2015) have been suggested as relevant treatment options for patients with EILO and closure at the glottic level. Speech therapy employs a variety of techniques and practices with the aim of relieving laryngeal tension, facilitating respiratory control and diaphragmatic breathing through muscle relaxation and breathing exercises (MathersSchmidt, 2001; Newsham et al., 2002). It has been shown to be effective in reducing breathing difficulties and wheezing (Christopher \& Morris, 2010; De Guzman, Ballif, Maurer, Hartnick, \& Raol, 2014; Martin, Blager, Gay, \& Wood, 1987; McFadden Jr \& Zawadski, 1996). Treatment duration has ranged from $3-4$ sessions (Brugman \& Simons, 1998), up to $3-20$ months for a more long-lasting recovery (Christopher \& Morris, 2010). Studies show increased short-term coping with VCD symptoms after speech therapy in 80 - 95\% of clients (De Guzman et al., 2014; Sullivan et al., 2001). The cognitive behavioural approach similarly focuses on diaphragmatic breathing and 
progressive muscle relaxation in combination with targeting of cognitive skills. A recent study, including 36 children and adolescents, demonstrated significant reduction in symptom ratings and symptom severity (Richards-Mauze \& Banez, 2014). Significant increases were also confirmed in participants' perception of perceived control and in their ability to cope with symptoms over the course of a four-session cognitive behavioural intervention (Richards-Mauze \& Banez, 2014). Psychotherapy is considered an alternative for patients assumed to have psychological co-morbidity (McQuaid et al., 1997; Olin et al., 2015). In cases of severe supraglottic obstruction, surgery is considered an effective treatment for a select group of patients (Mehlum, Walsted, Godballe, \& Backer, 2016; Maat et al., 2011; Norlander, Johansson, Jansson, Nordvall, \& Nordang, 2015). While appropriate posture and breathing are considered important in speech therapy and singing, the implications of a dysfunctional pattern of breathing on muscles and posture of the neck and upper thorax are, to date, rarely discussed in the literature with regard to voice rehabilitation, singing or EILO. The mechanisms of a dysfunctional breathing pattern and how this may interfere with posture and the laryngeal tract clearly need further elaboration for a more comprehensive understanding of EILO.

\section{LARYNGEAL STRUCTURES, MUSCLES AND POSITION}

The larynx is an extremely intricate structure; it is made up of cartilages unified by ligaments and fibrous membranes that are moved by a series of muscles (Standring, 2008). The space within the laryngeal lumen depends on its cartilaginous skeleton ${ }^{2}$, the vocal folds and aryepiglottic folds, and the movements of these structures. The larynx is located at the front of the cervical spine and is attached to the hyoid bone caudally by ligaments, membranes and the thyrohyoid muscle, which depresses the hyoid bone and elevates the larynx. Given the essential role of cervical posture in laryngeal functioning, it should be noted that the hyoid and laryngeal cartilages extend from level C3 (hyoid bone) to C6 (cricoid cartilage) (Standring, 2008). The larynx has a vital role in respiration,

\footnotetext{
${ }^{2}$ These are the single thyroid, cricoid and epiglottic cartilages, while the paired cartilages are the arytenoid, cuneiform, corniculate and tritiate.
} 
voice production and in preventing foreign objects from entering the lungs (i.e., a cough reflex is triggered if anything other than air enters the trachea). The lumen typically expands as the vocal and aryepiglottic folds abduct to allow for increased airflow when respiratory demands increase. The narrowing of the laryngeal tract that presents during exercise in some clients (e.g. EILO) places excessive physical stress on the lumen, subsequently causing respiratory distress and obstructing the airflow.

The muscles of the larynx comprise intrinsic and extrinsic muscles. The small intrinsic muscles ${ }^{3}$ produce movement of arytenoid cartilages as well as the adduction, abduction and tension of the vocal folds. The oblique arytenoids, aryepiglottic and thyroepiglottic muscles control the laryngeal inlet (Standring, 2008). The larger extrinsic muscles, which include the suprahyoid (the stylohyoids, mylohyoids and geniohyoids) and infrahyoid "strap" muscles (the thyrohyoids, sternothyroids, sternohyoids and omohyoids), keep the larynx in a stable and neutral position within the trachea (Van Houtte, Van Lierde, \& Claeys, 2011). A stable laryngeal position is believed to facilitate functioning of the intrinsic laryngeal muscles and reduce forces invoking closure of the vocal folds (Shipp, 1987). Given the location of the larynx, in front of the cervical spine and attached caudally to the hyoid bone, increased tension in suprahyoid and infrahyoid muscles (i.e. muscles raising and lowering the larynx) may alter the position of the larynx within the neck, and invoke tension and paradoxical forces in the laryngeal tract (Angsuwarangsee \& Morrison, 2002; Iwarsson \& Sundberg, 1998; Rubin, Mathieson, \& Blake, 2004). While increased tension in the infrahyoid group of muscles tends to pull the larynx downward, increased tension in the suprahyoid group may create a pull in the upward direction (Rubin et al., 2004; Van Houtte et al., 2011). Optimal neuromuscular coordination, proprioception and position of the larynx thus require a balanced tension between muscles pulling in the upward and downward directions.

Increased activation of muscles indirectly related to and surrounding the larynx may also impair laryngeal functioning, particularly in singing. The sternocleidomastoids (SCM), comprising a

\footnotetext{
3 The cricothyroids, aryepiglotticus, thyroarytenoids, thyroepiglotticus, cricoarytenoids and arytenoids.
} 
clavicular and a sternal part, are considered among the most important extra-laryngeal muscles involved in phonation (Kooijman et al., 2005). Increased tension in the SCM is commonly found in clients with voice disorders (Rubin, Blake, \& Mathieson, 2007) and in singers (Pettersen \& Westgaard, 2002). Increased tension in the trapezius during inhalation in demanding singing tasks, particularly when singing in the highest pitch, has been reported (Pettersen \& Westgaard, 2002). It has also been demonstrated that the trapezius muscles may respond to psychological stress with high activation levels despite the fact that no mechanical effort is needed (Waersted, Bjorklund, \& Westgaard, 1994). Such increased tension in the trapezius and SCM will habitually elevate the upper thorax and lift the ribcage, and may cause a shortening of the neck and the laryngeal tract.

It has further been established that the ideal position of the larynx for the fluency and coordination of laryngeal movements is a neutral or lower vertical position, as opposed to an elevated position that interferes with the laryngeal cartilaginous structures and may induce tightness and spasms in the larynx (Rubin et al., 2004; Van Houtte et al., 2011). When the diaphragm contracts and descends for inhalation, a downward mechanical force, or tracheal pull, is exerted. It has been shown that this pull moves the larynx into an ideal position for voice production (Iwarsson \& Sundberg, 1998) and facilitates glottal abduction to allow for increased airflow during phonation (Iwarsson, Thomasson, \& Sundberg, 1998). Reduced diaphragmatic breathing may therefore reduce the downward tracheobronchial pull and prevent the larynx from adopting an optimal position - an observation supported by radiographic findings indicating that laryngeal positions are higher in people with voice disorders when compared to people with no voice disorders (Lowell, Kelley, Colton, Smith, \& Portnoy). An elevated laryngeal position is assumed to reduce the quality of voice, as it adds stress to the lumen, provokes vocal fold adduction, produces tension and stiffness in laryngeal muscles and shortens the vocal tract (Iwarsson, 2001; Iwarsson \& Sundberg, 1998; Roy \& Leeper, 1993). Importantly, a lower position of the larynx may also invoke a higher lung volume (Iwarsson \& Sundberg, 1998). Thus, the lowering of an elevated larynx is often an explicit goal in voice therapy (Elliot, Sundberg, \& Gramming, 1997). 
Muscle tension dysphonia (MTD) is a diagnostic term used to refer to increased laryngeal musculoskeletal tension, and imbalance in the tension and synchronization of intrinsic and extrinsic laryngeal muscle function (Altman, Atkinson, \& Lazarus, 2005; Roy, 2003; Van Houtte et al., 2011). MTD is classified as primary or secondary. Primary MTD (i.e., "functional dysphonia") indicates dysphonia in the absence of identifiable laryngeal pathology, such as vocal fold lesions or paralysis, and accounts for up to $40 \%$ of the dysphonia seen in voice clinics (Altman et al., 2005; Dromey, Nissen, Roy, \& Merrill, 2008). Secondary MTD occurs concomitant to, and is associated with, underlying organic disorder (Van Houtte et al., 2011). Both types present with symptoms including hoarseness, vocal fatigue, reduced quality of voice production and vocal range, pain connected to voice use, tight muscles and neck stiffness (Craig et al., 2015). MTD is produced by psychological and/or personality factors (Roy \& Bless, 2000), incorrect vocal techniques, respiratory disturbance, previous infection(s) or as compensation for underlying disease (Van Houtte et al., 2011).

\section{HOW MAY POSTURAL DE-ALIGNMENTS AND DYSFUNCTIONAL BREATHING PATTERN INTERFERE WITH LARYNGEAL FUNCTION}

In a balanced and stable posture, the different segments of the body are balanced against each other in a way that allows for stability and flexibility. Balanced length, tension and coordination pattern of muscles and movements of the entire body also characterize postural stability. It is well established in voice therapy and vocal pedagogy that a balanced body and good postural alignment are important qualities for optimizing the quality of voice (Kooijman et al., 2005; Rubin et al., 2004; Schneider, Dennehy, \& Saxon, 1997; Wilson Arboleda \& Frederick, 2008). A neutral position of the cervical spine is particularly important in classical singing to minimize stress on muscles, bones and joints, and to offer a solid basis for cervical and laryngeal mobility (Kooijman et al., 2005; Pettersen \& Westgaard, 2002). Balanced tension in muscles of the neck is crucial for maintaining cervical stability and for optimizing laryngeal function and airflow (Mathieson et al., 2009; Rubin et al., 2004; Van Houtte et al., 2011). Conversely, de-alignment of the cervical spine, such as a forward 
head posture, may produce cervical hyperextension. This position not only restricts the range of cervical motion, it also affects the position of the larynx negatively, as the larynx is slightly elevated and moved anteriorly in the neck if the head posture is forward (Kooijman et al., 2005; $\mathrm{Ng} \&$ Bailey, 2006). A forward head posture and the associated elevated position of the larynx are thought to be the most important predictors for severity of voice quality problems (Kooijman et al., 2005). If breathing is high thoracic, which commonly involves increased activation of respiratory muscles otherwise involved in producing flexion, extension, rotation and lateral flexion of the neck, this may add further stress to the neck.

Besides its vital role in physical processes and in maintaining physiological homeostasis, respiration has a key role in motor control and postural stability (Chaitow, Bradley, \& Gilbert, 2014; Hodges, Gurfinkel, Brumagne, Smith, \& Cordo, 2002). The diaphragm has, for instance, a major role in respiration and in maintaining normal ventilation, but the muscle also makes a vital contribution to core stability and posture (Hodges, Sapsford, \& Pengel, 2007). Thus, if respiration is restricted, the postural activation of stabilization muscles weakens, further compromising the breathing pattern and stability of the spine (Hodges, Heijnen, \& Gandevia, 2001). The intention of breathing is primarily to meet metabolic requirements of the body by efficiently inhaling oxygen into and exhaling carbon dioxide out of the lungs. Breathing at rest is preferably abdominal and lower thoracic. It involves diaphragmatic action and little or no activity of accessory respiratory musculature or other compensatory structures. Ideally, thoracic structures should be compliant and elastic such that inspiration can flow without restrictions and the chest expand smoothly with a minimum of effort (Chaitow et al., 2014). In normal inhalation, the diaphragm descends, while the ribs rise and expand laterally to increase the transverse dimensions of the thorax (Chaitow et al., 2014). In the expiration phase, the diaphragm and chest wall usually resume their initial position. If diaphragmatic movement is reduced, expansion of the trunk in the vertical direction and elevation of the shoulders tend to compensate for the lack of diaphragmatic descent and normal expansion of the chest, such that respiratory muscles involved in lifting and stabilizing the upper part of the thorax become stressed 
and increasingly activated. Such a pattern seems to be reflected in the substantial muscle activity revealed in the upper trapezius, scalene, sternocleidomastoids and the posterior neck muscle group in classical singers during inhalation (Pettersen \& Westgaard, 2002, 2005), and also in athletes

presenting with EILO seen in physiotherapy (Kolnes, 2016b). While a minor activation of respiratory muscles of the upper rib cage is part of normal respiration, changes are likely to occur in response to increased respiratory demands. Indeed, reduced range of thoracic mobility will affect respiratory efficacy, both during rest and exercise.

In support of the view that sensitivity of laryngeal structures is related to the ANS, specialized centres and neurons in the brainstem control autonomic breathing and regulate the rhythm of breathing according to bodily demands. While there is no clear evidence for a central origin of the neural coordination of movements of the airways, Del Negro and colleagues have identified neurons that are rhythmically active during inspiration and that project to a part of the medulla (the hypoglossal nucleus) containing motoneurons important for keeping the airway open (Kottick \& Del Negro, 2015; Revill et al., 2015; Vann, Pham, Hayes, Kottick, \& Del Negro, 2016). A recent study, which found elevated activation of intrinsic laryngeal muscles and the trapezius following whole body ANS activation, supports the idea of a connection between laryngeal muscle tension and acute stress (Helou, Wang, Ashmore, Rosen, \& Abbott, 2013). These findings may shed light on the interrelatedness between breathing and psychological states, and, at least partially, on how high levels of emotional stress and nervousness about sporting performance may, in some athletes, contribute to laryngeal sensitization during inhalation.

\section{TREATMENT OPTIONS TO OPTIMIZE VOICE QUALITY AND LARYNGEAL FUNCTION}

A number of direct and indirect treatment approaches aimed at promoting laryngeal function have been outlined in clinical voice therapy and vocal pedagogy. Indirect approaches take lifestyle factors, psychological aspects and voice behaviours that may have an impact on the voice problems into account, and if required, these are altered through patient education and vocal hygiene (Mackenzie, 
Millar, Wilson, Sellars, \& Deary, 2001; Van Houtte et al., 2011). Direct approaches include vocal exercises to facilitate vocal techniques and circumlaryngeal massage to reduce extra-laryngeal muscle tension and optimize voice production. A few systematic reviews and randomized studies have established that a combination of indirect and direct approaches is the most effective intervention for treating muscle tension dysphonia when compared to no intervention (Carding, Horsley, \& Docherty, 1999; Craig et al., 2015; Gillivan-Murphy, Drinnan, O'Dwyer, Ridha, \& Carding, 2006; Mackenzie et al., 2001; J. Ruotsalainen, Sellman, Lehto, \& Verbeek, 2008; J. H. Ruotsalainen, Sellman, Lehto, Jauhiainen, \& Verbeek, 2007).

Traditionally, direct treatment methods address increased tension of muscles and structures in the larynx and the laryngeal area (local anterior neck approach). Manual laryngeal therapy is a method broadly implemented in patients with increased laryngeal elevation and excessive tension in laryngeal and extra-laryngeal muscles (Mathieson et al., 2009; Roy, Bless, Heisey, \& Ford, 1997; Roy \& Ferguson, 2001; Van Lierde, Bodt, Dhaeseleer, Wuyts, \& Claeys, 2010). The major aim is to restore normal phonatory function by reducing muscle tension in the laryngeal region, on the assumption that decreased muscular tension will have a beneficial effect on laryngeal height and improve voice qualities in individuals with muscle tension dysphonia. The intervention is based on assessment of laryngeal height and muscular tension in the laryngeal area, and a number of palpatory techniques are applied, including rotational massage, kneading and stretching of laryngeal muscles (Mathieson et al., 2009; Roy et al., 1997; Roy \& Leeper, 1993; Van Lierde et al., 2010). There is, however, little evidence to confirm the effectiveness of the techniques or to suggest which palpatory indicators should be applied to assess laryngeal elevation and tension (Khoddami, Ansari, \& Jalaie, 2015). This may indicate that the value of such techniques depends on the experience and skills of the therapist.

In line with increasing recognition of the relationship between body posture, laryngeal muscles and laryngeal functioning over the last decade, it has been proposed that the focus of the management of voice problems needs to extend beyond muscles and structures of the anterior neck. 
A number of authors contend that a whole body approach is imperative to optimize evaluation and treatment in order to achieve meaningful improvements in people with voice problems ( Cardoso, Meneses, \& Lumini-Oliveira, 2017; Craig et al., 2015; Rubin et al., 2007; Tomlinson \& Archer, 2015) and in singers (Kennard, Lieberman, Saaid, \& Rolfe, 2015; Pettersen \& Westgaard, 2005; Staes et al., 2011). Rubin et al. (2007) discussed how a broader physical therapy approach, including evaluation of muscular tension, stability and position of the neck and upper thoracic spine, as well as the interrelatedness between these dimensions, was helpful in the management of voice problems in 26 patients. Rubin et al. have previously outlined how repositioning of the cervical spine, stretching and releasing tension in muscles of the neck attached to the hyoid bone, and strengthening deep neck stabilizers, are helpful methods for relieving problems associated with the larynx (2004). Findings from a case series reveal improved patient outcomes regarding pain, functional status, voice quality, jaw opening and range of cervical motion in patients with MTD (Tomlinson \& Archer, 2015). The intervention consisted of a structured programme using manual therapy techniques, exercise and stress management, and addressed muscle imbalances, poor posture and symptoms of stress (Tomlinson \& Archer, 2015). Anterior neck manual therapy was combined with manual therapy focusing on muscles of the posterior neck, the thoracic musculature, temporomandibular joints, rib cage intercostal muscles and diaphragm release, in addition to exercises improving posture and relaxation (Tomlinson \& Archer, 2015). In a study investigating the role of a specialized physical therapy programme as an adjunct to standard voice therapy, patients treated with voice therapy had statistically greater improvement when compared to no treatment (Craig et al., 2015). Physical therapy was offered to patients who had muscular tension (e.g., in tongue and neck) in addition to muscle tension dysphonia. An interesting finding was distinct, though not significant, improvements among patients treated with physical therapy alone (Craig et al., 2015). The physical therapy programme included manual therapy and patient education, and exercises addressing posture, muscle imbalance of the anterior neck, and the cervical range of motion, as well as symptoms related to stress (Craig et al., 2015). 
In addition to a neutral posture of the cervical spine, normal postural alignment is imperative for the level of performance in singing (Wilson Arboleda \& Frederick, 2008). A sound foundation for singing is an optimal standing position complying with the normal postural alignment of the body. If postural alignment is ideal, a perpendicular line can be drawn running through the mastoid process, anterior to the shoulder joint, posterior to the hip joint, anterior to the knee joint and anterior to the ankle joint. Accordingly, approaches focusing on postural alignment of the whole body may be more common within the field of singing than in MTD. Staes et al. (2011) aimed to optimize postural alignment, joint mobility and muscular stability of the entire body in a classical singing student through an individually modified physical therapy intervention including manual therapy and exercises. Examination of the body revealed a thoracic breathing pattern, a lack of lateral expansion of the thorax and lack of abdominal breathing support in the client. Postural alignment was also ineffective, and a forward head posture with concomitant lack of cervical stability and shoulder protraction was observed. After a four-month intervention, the results showed improved postural alignment and voice parameters in the singer (Staes et al., 2011). The work of Kennard et al. (2015) focused on the influence of postural alignment on laryngeal functioning, and showed statistically significant effects following specific laryngeal manipulation and postural manual therapy on voice quality in twelve singers. Specific laryngeal manipulation in this study involved manual treatment of tight laryngeal structures that constrict movement, stretching of infrahyoid muscles, and articulation of joints with restricted range of movement (Kennard et al., 2015). To promote optimal postural alignment, postural manual therapy was used to target mobility and stabilizing structures influencing the voice production, and included stretching and massage of the sternocleidomastoids, scalene and trapezius muscles, as well as articulation of the cervical and thoracic spine (Kennard et al., 2015). The authors proposed that articulation of the cervical and thoracic spine would have a positive effect on the stabilizing cervical muscles and on posture, subsequently influencing the airway flow and reducing tension in the lumen and on vocal structures. 


\section{DISCUSSION}

As in voice and singing difficulties, the structure that shows sensitization and that is central to the observed abnormalities in exercise-induced laryngeal obstruction, is the larynx. The clinical factors that determine voice quality therefore also appear highly relevant in terms of understanding laryngeal dysfunction during excessive exercise when respiratory demands increase. Factors that directly or indirectly contribute to laryngeal dysfunction and impaired quality of voice include laryngeal structures and muscles, extra-laryngeal muscles, position of the larynx, and postural de-alignments, in particular of the cervical spine. In addition, a dysfunctional breathing pattern will affect the function of the larynx by causing cervical muscular tension and de-alignment. It can be presumed that a neutral position of the larynx, balanced tension in the laryngeal muscles, and neutral posture of the cervical spine are essential clinical features influencing laryngeal function in athletes struggling with symptoms of EILO. Instead of facilitating the airflow - a prerequisite in most sports - it can be assumed that an inappropriate cervical posture, such as a forward head posture, which implies an elevated position of the larynx, produces inspiratory instability in the lumen as the physical intensity increases.

A pattern of upper chest breathing accompanied by increased muscle tension in respiratory muscles, possibly triggered by increased parasympathetic activity as previously shown in endurance athletes (Filipe, Falcao-Reis, Castro-Correia, \& Barros, 2003; Kaltsatou, Kouidi, Fotiou, \& Deligiannis, 2011), is frequently seen in young elite athletes with EILO receiving physical therapy for their breathing difficulties (Kolnes, 2016b). If upper chest breathing becomes the habitual breathing pattern, compensatory changes such as increased activation of respiratory muscles, absence of diaphragmatic descent and postural de-alignments characterized by a forward head posture and increased extension of the lower cervical spine are likely to emerge (Kapreli, Vourazanis, \& Strimpakos, 2008; Kolnes, 2016a; Perri \& Halford, 2004). Eventually, proprioception and neuromuscular control of the muscles of the neck become disrupted and the neuromuscular coordination of cervical movements during respiration is impaired, subsequently affecting the 
position of the larynx and laryngeal movements. It could be hypothesized that over time, such compensatory mechanisms of the neck will severely affect the respiratory system, particularly during exercise of high physical intensity, as the upward thoracic breathing movements and hyperextension of the cervical spine are prone to intensify as a response to increased respiratory effort, further reinforcing the sensitization and narrowing of the larynx in individuals with symptoms of EILO. While inhalation without restriction is required to supply the working muscles with oxygen, the "entry" to the breathing tube gradually becomes constricted. Instead of opening of the lumen to allow for increased airflow, the more the athletes struggle to inhale, the more the upward breathing movement and the de-alignment of the neck intensify, and the greater the problems with inhalation. Thus, the athletes are subjected to a vicious circle of striving to inhale, inappropriate posture and laryngeal obstruction.

Furthermore, it may be deduced that good postural alignment, stability and flexibility of the entire body may counteract de-alignments of the upper body (e.g. in the cervical spine and position of laryngeal structures). Even minor divergences in posture and bodily axis can produce shifts in the centre of gravity and cause restructuring mechanisms to occur from feet to head. For instance, if the standing position is characterized by the perpendicular line being posterior instead of anterior to the ankle joint, the person may compensate with a forward head posture in order to be able to maintain a stable balance. Thus, to arrive at a stable posture and to counteract de-alignments in the upper body, it is imperative to create a solid platform for the body, to ensure that the person is able to stand steady on his or her feet. Such a standing position requires modest muscular effort and allows for spontaneous changes in posture and breathing pattern. Clinical experiences have demonstrated that the breathing typically become less restrained and more diaphragmatic as the person's posture alters from being rigid and inflexible to becoming more balanced and flexible (Kolnes, 2016a). Consequently, it could be assumed that tension in the neck and laryngeal area eases if the breathing pattern is normalized. 
When treating complications localized at the laryngeal level - whether related to muscle tension dysphonia (Cardoso et al., 2017; Craig et al., 2015; Rubin et al., 2007; Tomlinson \& Archer, 2015), voice difficulties in classical singing (Kennard et al., 2015; Pettersen \& Westgaard, 2005; Staes et al., 2011; Wilson Arboleda \& Frederick, 2008) or inhalation problems during excessive exercise (Kolnes, 2016b) - it thus appears necessary to expand the focus from primarily targeting laryngeal structures and muscles of the anterior neck, particularly if such approaches are not effective, to include treatment approaches that address the entire system of which the larynx is a part. This may include targeting the breathing pattern and postural de-alignments of the entire body, as these appear fundamental for optimal respiration and quality of voice. This implies that before a treatment method is selected for a client with EILO with no organic origin, the client should first undergo a thorough physical examination to identify constrictions in the body as a whole, such as postural de-alignments and dysfunctional breathing pattern, as these interact with and make essential contributions to the mechanisms causing laryngeal tightness during vigorous exercise.

EILO requires a multidisciplinary approach, particularly during the investigative stage; physical therapists possess particular skills and competence in examining the breathing pattern and postural de-alignments, and should therefore be included in the evaluation process. To facilitate improvement in these clients, a detailed knowledge of the functioning of the respiratory system and the associated biomechanics, as well as of cognitive and psychological aspects that may affect respiration, would seem to be required. Given that breathing is in part regulated by the autonomic nervous system, and that adaptations need to be integrated in the person as well as in the neural system, it is essential to recognize that it will take time to alter the respiration and for the client to acquire and integrate a normalized breathing pattern. Since clients respond differently to interventions, individually tailored programmes seem crucial here (Sandnes et al., 2013), as does collaboration with parents and physical trainers to ensure that the teenage client is given the time and support necessary for recovery. It is important to keep in mind that altering an individual's pattern of breathing is a long-term process. The focus should not necessarily be on breathing techniques, but on 
releasing tension (e.g., in the jaws and shoulder girdle) and acquiring a body posture in which the various segments are balanced against each other in a way that allows for stability and flexibility.

It may in principle be appropriate to consider distinguishing between variations of EILO.

Primary EILO could refer to inspiratory respiratory difficulties accompanying medical conditions, surgery, scars and tumours at the laryngeal level. Secondary EILO could be the label for the narrowing of the laryngeal tract during intensive exercise caused by excessive tension in laryngeal muscles and an elevated larynx, as well as by postural de-alignments and increased tension in respiratory muscles associated with a dysfunctional breathing pattern. This understanding suggests that laryngeal dysfunction is triggered by "global" dynamics, implying that the laryngeal tract is part of a functionally integrated and coordinated system of bodily function and structures. Thus, a question that clearly needs to be raised is whether exercise-induced obstruction at the laryngeal level promotes or is a consequence of bodily de-alignment and upper chest breathing pattern and accompanying de-alignment of the cervical spine. Given the complicated nature of laryngeal functioning during exercise, research that captures the clinical complexity of EILO is clearly needed, both to clarify dimensions that should be included in assessing clinical symptoms of EILO and to explore long-term effects of treatment approaches. ${ }^{4}$

\section{CONCLUSION}

Understanding of EILO is incomplete and there are currently few reports of treatments with longterm effects in athletes. In keeping with an understanding of the body as a functionally integrated entity, implying that divergence in one bodily function or structure may create change in other parts, it is imperative that posture and breathing pattern are taken into account in the understanding of bodily mechanisms that may contribute to sensitization of the laryngeal tract and inspiratory

\footnotetext{
4 A pilot study has recently been initiated, in which subjective clinical symptoms, measures of lung function, bronchial hyperresponsiveness (BHR), and parasympathetic activity and movements of the larynx during exercise (measured by a CLE-test) will be investigated in clients newly diagnosed with EILO. The data will be gathered before and after five months of physical therapy addressing the whole body.
} 
breathing difficulties, such as EILO. Likewise, postural de-alignments and a dysfunctional breathing

pattern need to be identified and addressed in treatment approaches directed at EILO.

Declaration of interests: The authors report no declaration of interests.

\section{$\underline{\text { References }}$}

Al-Alwan, A., \& Kaminsky, D. (2012). Vocal cord dysfunction in athletes: clinical presentation and review of the literature. The Physician and sportsmedicine, 40(2), 22-27. doi:http://dx.doi.org/10.3810/psm.2012.05.1961

Altman, K. W., Atkinson, C., \& Lazarus, C. (2005). Current and emerging concepts in muscle tension dysphonia: A 30-month review. Journal of Voice, 19(2), 261-267. doi:http://dx.doi.org/10.1016/i.jvoice.2004.03.007

Angsuwarangsee, T., \& Morrison, M. (2002). Extrinsic Laryngeal Muscular Tension in Patients with Voice Disorders. Journal of Voice, 16(3), 333-343. doi:10.1016/S0892-1997(02)00105-4

Ayres, J. G., \& Gabbott, P. L. A. (2002). Vocal cord dysfunction and laryngeal hyperresponsiveness: A function of altered autonomic balance? Thorax, 57(4), 284-285. doi:http://dx.doi.org/10.1136/thorax.57.4.284

Ayres, J. G., \& Mansur, A. H. (2011). Vocal Cord Dysfunction and Severe Asthma: Considering the Total Airway. American Journal of Respiratory \& Critical Care Medicine, 184(1), 2-3.

Benninger, C., Parsons, J. P., \& Mastronarde, J. G. (2011). Vocal cord dysfunction and asthma. Current Opinion in Pulmonary Medicine, 17(1), 45-49.

Boulet, L. P. (2012). Cough and upper airway disorders in elite athletes: a critical review. British Journal of Sports Medicine, 46(6), 417-421.

Brugman, S. M., \& Simons, S. M. (1998). Vocal cord dysfunction: Don't mistake it for asthma. Physician and Sportsmedicine, 26(5), 63-85.

Carding, P. N., Horsley, I. A., \& Docherty, G. J. (1999). A study of the effectiveness of voice therapy in the treatment of 45 patients with nonorganic dysphonia. Journal of Voice, 13(1), 72-104.

Cardoso, R., Meneses, R. F., \& Lumini-Oliveira, J. (2017). The Effectiveness of Physiotherapy and Complementary Therapies on Voice Disorders: A Systematic Review of Randomized Controlled Trials. Frontiers in Medicine, 4(45). doi:10.3389/fmed.2017.00045

Castelli, W. A., Ramirez, P. C., \& Nasjleti, C. E. (1973). Linear growth study of the pharyngeal cavity. Journal of Dental Research, 52(6), 1245-1248.

Chaitow, L., Bradley, D., \& Gilbert, C. (2014). The structure and function of breathing. In D. B. L Chaitow, C Gilbert (Ed.), Recognizing and treating breathing disorders (Vol. Second edition, pp. 23-43). Edingburgh: Churchill Livingstone Elsevier.

Christensen, P. M., Thomsen, S. F., Rasmussen, N., \& Backer, V. (2010). Exercise-induced laryngeal obstructions objectively assessed using EILOMEA. European Archives of Oto-Rhino-Laryngology, 267(3), 401-407. doi:http://dx.doi.org/10.1007/s00405-009-1113-6

Christensen, P. M., Thomsen, S. F., Rasmussen, N., \& Backer, V. (2011). Exercise-induced laryngeal obstructions: Prevalence and symptoms in the general public. European Archives of Oto-RhinoLaryngology, 268(9), 1313-1319. doi:http://dx.doi.org/10.1007/s00405-011-1612-0

Christopher, K. L., \& Morris, M. J. (2010). Vocal Cord Dysfunction, Paradoxic Vocal Fold Motion, or Laryngomalacia? Our Understanding Requires an Interdisciplinary Approach. Otolaryngologic Clinics of North America, 43(1), 43-66. doi:http://dx.doi.org/10.1016/j.otc.2009.12.002

Craig, J., Tomlinson, C., Stevens, K., Kotagal, K., Fornadley, J., Jacobson, B., . . Francis, D. O. (2015). Combining voice therapy and physical therapy: A novel approach to treating muscle tension dysphonia. J Commun Disord, 58, 169-178. doi:10.1016/j.jcomdis.2015.05.001 
De Guzman, V., Ballif, C. L., Maurer, R., Hartnick, C. J., \& Raol, N. (2014). Validation of the Dyspnea Index in Adolescents With Exercise-Induced Paradoxical Vocal Fold Motion. JAMA Otolaryngology-Head \& Neck Surgery, 140(9), 823-828.

Dromey, C., Nissen, S. L., Roy, N., \& Merrill, R. M. (2008). Articulatory changes following treatment of muscle tension dysphonia: Preliminary acoustic evidence. Journal of Speech, Language, and Hearing Research, 51(1), 196-208. doi:http://dx.doi.org/10.1044/1092-4388\%282008/015\%29

Elliot, N., Sundberg, J., \& Gramming, P. (1997). Physiological aspects of a vocal exercise. Journal of Voice, 11(2), 171-177. doi:http://dx.doi.org/10.1016/S0892-1997\%2897\%2980075-6

Filipe, J. A., Falcao-Reis, F., Castro-Correia, J., \& Barros, H. (2003). Assessment of autonomic function in high level athletes by pupillometry. Auton Neurosci, 104(1), 66-72.

Gilbert, C. (2003). Clinical applications of breathing regulation - Beyond anxiety management. Behavior Modification, 27(5), 692-709. doi:10.1177/0145445503256322

Gilbert, C. (2014). Interaction of psychological and emotional variabes with breathing dysfunction. In B. D. Chaitow L, Gilbert C (Ed.), Recognizing and treating breathing disorders (pp. 79-91). Edingburgh: Chruchill Livingstone Elsevier.

Gillivan-Murphy, P., Drinnan, M. J., O'Dwyer, T. P., Ridha, H., \& Carding, P. (2006). The Effectiveness of a Voice Treatment Approach for Teachers With Self-Reported Voice Problems. Journal of Voice, 20(3), 423-431. doi:http://dx.doi.org/10.1016/i.jvoice.2005.08.002

Heimdal, J.-H. M. D., Roksund, O. D. M., Halvorsen, T. M. D., Skadberg, B. T. M. D., \& Olofsson, J. M. D. (2006). Continuous Laryngoscopy Exercise Test: A Method for Visualizing Laryngeal Dysfunction during Exercise. Laryngoscope, 116(1), 52-57.

Helou, L. B., Wang, W., Ashmore, R. C., Rosen, C. A., \& Abbott, K. V. (2013). Intrinsic laryngeal muscle activity in response to autonomic nervous system activation. Laryngoscope, 123(11), 2756-2765. doi:http://dx.doi.org/10.1002/lary.24109

Hocevar-Boltezar, I., Krivec, U., \& Sereg-Bahar, M. (2017). Laryngeal sensitivity testing in youth with exerciseinducible laryngeal obstruction. International Journal of Rehabilitation Research, 40(2), 146-151. doi:https://dx.doi.org/10.1097/MRR.0000000000000222

Hodges, P. W., Gurfinkel, V. S., Brumagne, S., Smith, T. C., \& Cordo, P. C. (2002). Coexistence of stability and mobility in postural control: evidence from postural compensation for respiration. Exp Brain Res, 144(3), 293-302. doi:10.1007/s00221-002-1040-x

Hodges, P. W., Heijnen, I., \& Gandevia, S. C. (2001). Postural activity of the diaphragm is reduced in humans when respiratory demand increases. J Physiol, 537(Pt 3), 999-1008.

Hodges, P. W., Sapsford, R., \& Pengel, L. H. (2007). Postural and respiratory functions of the pelvic floor muscles. Neurourol Urodyn, 26(3), 362-371. doi:10.1002/nau.20232

Idrees, M., \& Fitzgerald, J. M. (2015). Vocal cord dysfunction in bronchial asthma. A review article. Journal of Asthma, 52(4), 327-335. doi:http://dx.doi.org/10.3109/02770903.2014.982288

Iwarsson, J. (2001). Effects of Inhalatory Abdominal Wall Movement on Vertical Laryngeal Position During Phonation. Journal of Voice, 15(3), 384-394. doi:http://doi.org/10.1016/S08921997(01)00040-6

Iwarsson, J., \& Sundberg, J. (1998). Effects of lung volume on vertical larynx position during phonation. Journal of Voice, 12(2), 159-165. doi:http://dx.doi.org/10.1016/S0892-1997(98)80035-0

Iwarsson, J., Thomasson, M., \& Sundberg, J. (1998). Effects of lung volume on the glottal voice source. Journal of Voice, 12(4), 424-433. doi:http://dx.doi.org/10.1016/S0892$1997 \% 2898 \% 2980051-9$

Johansson, H., Norlander, K., Berglund, L., Janson, C., Malinovschi, A., Nordvall, L., . . Emtner, M. (2015). Prevalence of exercise-induced bronchoconstriction and exercise-induced laryngeal obstruction in a general adolescent population. Thorax, 70(1), 57-63. doi:http://dx.doi.org/10.1136/thoraxinl2014-205738

Kaltsatou, A., Kouidi, E., Fotiou, D., \& Deligiannis, P. (2011). The use of pupillometry in the assessment of cardiac autonomic function in elite different type trained athletes Eur J Appl Physiol, 111(9), 20792087. 
Kapreli, E., Vourazanis, E., \& Strimpakos, N. (2008). Neck pain causes respiratory dysfunction. Medical Hypotheses, 70(5), 1009-1013. doi:10.1016/j.mehy.2007.07.050

Kennard, E. J., Lieberman, J., Saaid, A., \& Rolfe, K. J. (2015). A Preliminary Comparison of Laryngeal Manipulation and Postural Treatment on Voice Quality in a Prospective Randomized Crossover Study. Journal of Voice, 29(6), 751-754.

Khoddami, S. M., Ansari, N. N., \& Jalaie, S. (2015). Review on Laryngeal Palpation Methods in Muscle Tension Dysphonia: Validity and Reliability Issues. Journal of Voice, 29(4), 459-468. doi:https://doi.org/10.1016/j.jvoice.2014.09.023

Kolnes, L.-J. (2016a). Exercise and physical therapy help restore body and self in clients with severe anorexia nervosa. Journal of Bodywork and Movement Therapies. doi:http://dx.doi.org/10.1016/j.jbmt.2016.09.005

Kolnes, L.-J. (2016b). Is physiotheraphy a relevant treatment approach for exercise induced respiratory problems? (Er fysioterapi relevant i behandling av anstrengelsesutløste pusteproblemer?). Norwegian Sports Medicin, 31(4), 6-9.

Kooijman, P. G. C., De Jong, F. I. C. R. S., Oudes, M. J., Huinck, W., Van Acht, H., \& Graamans, K. (2005). Muscular tension and body posture in relation to voice handicap and voice quality in teachers with persistent voice complaints. Folia Phoniatrica et Logopaedica, 57(3), 134-147. doi:http://dx.doi.org/10.1159/000084134

Kottick, A., \& Del Negro, C. A. (2015). Synaptic depression influences inspiratory-Expiratory phase transition in Dbx1 interneurons of the prebotzinger complex in neonatal mice. Journal of Neuroscience, 35(33), 11606-11611. doi:http://dx.doi.org/10.1523/JNEUROSCI.0351-15.2015

Liyanagedara, S., McLeod, R., \& Elhassan, H. A. (2016). Exercise induced laryngeal obstruction: a review of diagnosis and management. European Archives of Oto-Rhino-Laryngology, 1-9. doi:http://dx.doi.org/10.1007/s00405-016-4338-1

Lowell, S. Y., Kelley, R. T., Colton, R. H., Smith, P. B., \& Portnoy, J. E. Position of the hyoid and larynx in people with muscle tension dysphonia. Laryngoscope. doi:http://dx.doi.org/10.1002/lary.22482

Mackenzie, K., Millar, A., Wilson, J. A., Sellars, C., \& Deary, I. J. (2001). Is voice therapy an effective treatment for dysphonia? A randomised controlled trial. British Medical Journal, 323(7314), 658-661.

Martin, R. J., Blager, F. B., Gay, M. L., \& Wood, I. R. P. (1987). Paradoxic vocal cord motion in presumed asthmatics. Seminars in Respiratory Medicine, 8(4), 332-337.

Masaoka, Y., \& Homma, I. (1997). Anxiety and respiratory patterns: their relationship during mental stress and physical load. International Journal of Psychophysiology, 27(2), 153-159. doi:Doi 10.1016/S01678760(97)00052-4

Masaoka, Y., \& Homma, I. (2001). The effect of anticipatory anxiety on breathing and metabolism in humans. Respir Physiol, 128(2), 171-177. doi:10.1016/s0034-5687(01)00278-x

Mathers-Schmidt, B. A. (2001). Paradoxical vocal fold motion: A tutorial on a complex disorder and the speech-language pathologist's role. American Journal of Speech-Language Pathology, 10(2), 111125. doi:http://dx.doi.org/10.1044/1058-0360\%282001/012\%29

Mathieson, L., Hirani, S. P., Epstein, R., Baken, R. J., Wood, G., \& Rubin, J. S. (2009). Laryngeal Manual Therapy: A Preliminary Study to Examine its Treatment Effects in the Management of Muscle Tension Dysphonia. Journal of Voice, 23(3), 353-366. doi:http://dx.doi.org/10.1016/j.jvoice.2007.10.002

McFadden Jr, E. R., \& Zawadski, D. K. (1996). Vocal cord dysfunction masquerading as exercise-induced asthma: A physiologic cause for 'choking' during athletic activities. American Journal of Respiratory and Critical Care Medicine, 153(3), 942-947.

McQuaid, E. L., Spieth, L. E., \& Spirito, A. (1997). The pediatric psychologist's role in differential diagnosis: Vocal-cord dysfunction presenting as asthma. Journal of Pediatric Psychology, 22(5), 739-748. doi:http://dx.doi.org/10.1093/ipepsy/22.5.739

Mehlum, C. S., Walsted, E. S., Godballe, C., \& Backer, V. (2016). Supraglottoplasty as treatment of exercise induced laryngeal obstruction (EILO). European Archives of Oto-Rhino-Laryngology, 273(4), 945-951. doi:http://dx.doi.org/10.1007/s00405-015-3823-2 
Morris, M. J., \& Christopher, K. L. (2010). Diagnostic criteria for the classification of vocal cord dysfunction. Chest, 138(5), 1213-1223. doi:http://dx.doi.org/10.1378/chest.09-2944

Maat, R. C., Hilland, M., Roksund, O. D., Halvorsen, T., Olofsson, J., Aarstad, H. J., \& Heimdal, J. H. (2011). Exercise-induced laryngeal obstruction: Natural history and effect of surgical treatment. European Archives of Oto-Rhino-Laryngology, 268(10), 1485-1492. doi:http://dx.doi.org/10.1007/s00405-011-1656-1

Maat, R. C., Roksund, O. D., Halvorsen, T., Skadberg, B. T., Olofsson, J., Ellingsen, T. A., ... Heimdal, J. H. (2009). Audiovisual assessment of exercise-induced laryngeal obstruction: Reliability and validity of observations. European Archives of Oto-Rhino-Laryngology, 266(12), 1929-1936. doi:http://dx.doi.org/10.1007/s00405-009-1030-8

Newman, K. B., Mason, I. U. G., \& Schmaling, K. B. (1995). Clinical features of vocal cord dysfunction. American Journal of Respiratory and Critical Care Medicine, 152(4 I), 1382-1386.

Newsham, K. R., Klaben, B. K., Miller, V. J., \& Saunders, J. E. (2002). Paradoxical vocal-cord dysfunction: Management in athletes. Journal of Athletic Training, 37(3), 325-328.

$\mathrm{Ng}$, M. L., \& Bailey, R. L. (2006). Acoustic changes related to laryngeal examination with a rigid telescope. Folia Phoniatrica et Logopaedica, 58(5), 353-362. doi:http://dx.doi.org/10.1159/000094569

Nielsen, E. W., Hull, J. H., \& Backer, V. (2013). High prevalence of exercise-induced laryngeal obstruction in athletes. Med Sci Sports Exerc, 45(11), 2030-2035. doi:10.1249/MSS.0b013e318298b19a

Norlander, K., Johansson, H., Jansson, C., Nordvall, L., \& Nordang, L. (2015). Surgical treatment is effective in severe cases of exercise-induced laryngeal obstruction: A follow-up study. Acta Oto-Laryngologica, 135(11), 1152-1159. doi:http://dx.doi.org/10.3109/00016489.2015.1062548

Olin, J. T., Clary, M. S., Deardorff, E. H., Johnston, K., Morris, M. J., Sokoya, M., . . Christopher, K. L. (2015). Inducible laryngeal obstruction during exercise: Moving beyond vocal cords with new insights. Physician and Sportsmedicine, 43(1), 13-21. doi:http://dx.doi.org/10.1080/00913847.2015.1007026

Perkner, J. J., Fennelly, M. K. P., Balkissoon, R., Bartelson, B. B., Ruttenber, J., Wood, I. R. P., \& Newman, L. S. (1998). Irritant-associated vocal cord dysfunction. Journal of Occupational and Environmental Medicine, 40(2), 136-143. doi:http://dx.doi.org/10.1097/00043764-199802000-00009

Perri, M. A., \& Halford, E. (2004). Pain and faulty breathing: A pilot study. Journal of Bodywork and Movement Therapies, 8(4), 297-306. doi:http://dx.doi.org/10.1016/S1360$\underline{8592 \% 2803 \% 2900085-8}$

Pettersen, V., \& Westgaard, R. H. (2002). Muscle activity in the classical singer's shoulder and neck region. Logopedics Phoniatrics Vocology, 27(4), 169-178. doi:http://dx.doi.org/10.1080/140154302762493225

Pettersen, V., \& Westgaard, R. H. (2005). The Activity Patterns of Neck Muscles in Professional Classical Singing. Journal of Voice, 19(2), 238-251. doi:http://dx.doi.org/10.1016/i.jvoice.2004.02.006

Powell, S. A., Nguyen, C. T., Gaziano, J., Lewis, V., Lockey, R. F., \& Padhya, T. A. (2007). Mass psychogenic illness presenting as acute stridor in an adolescent female cohort. Annals of Otology, Rhinology and Laryngology, 116(7), 525-531.

Revill, A. L., Vann, N. C., Akins, V. T., Kottick, A., Gray, P. A., Del Negro, C. A., \& Funk, G. D. (2015). Dbx1 precursor cells are a source of inspiratory XII premotoneurons. eLife, 4 (DECEMBER2015) (no pagination)(e12301). doi:http://dx.doi.org/10.7554/eLife.12301

Richards-Mauze, M. M., \& Banez, G. A. (2014). Vocal Cord Dysfunction: Evaluation of a Four-Session Cognitive-Behavioral Intervention. Clinical Practice in Pediatric Psychology, 2(1), 27-38.

Roksund, O. D., Heimdal, J. H., Olofsson, J., Maat, R. C., \& Halvorsen, T. (2015). Larynx during exercise: the unexplored bottleneck of the airways. European Archives of Oto-Rhino-Laryngology, 272(9), 21012109. doi:http://dx.doi.org/10.1007/s00405-014-3159-3

Roksund, O. D., Maat, R. C., Heimdal, J. H., Olofsson, J., Skadberg, B. T., \& Halvorsen, T. (2009). Exercise induced dyspnea in the young. Larynx as the bottleneck of the airways. Respiratory Medicine, 103(12), 1911-1918. doi:http://dx.doi.org/10.1016/j.rmed.2009.05.024

Roy, N. (2003). Functional dysphonia. Curr Opin Otolaryngol Head Neck Surg, 11(3), 144-148. 
Roy, N., \& Bless, D. M. (2000). Personality traits and psychological factors in voice pathology: a foundation for future research. Journal of speech, language, and hearing research : JSLHR, 43(3), 737-748.

Roy, N., Bless, D. M., Heisey, D., \& Ford, C. N. (1997). Manual circumlaryngeal therapy for functionaldysphonia: An evaluation of short- and long-term treatment outcomes. Journal of Voice, 11(3), 321-331. doi:http://dx.doi.org/10.1016/S0892-1997(97)80011-2

Roy, N., \& Ferguson, N. A. (2001). Formant frequency changes following manual circumlaryngeal therapy for functional dysphonia: Evidence of laryngeal lowering? Journal of Medical Speech-Language Pathology, 9(3), 169-175.

Roy, N., \& Leeper, H. A. (1993). Effects of the manual laryngeal musculoskeletal tension reduction technique as a treatment for functional voice disorders: Perceptual and acoustic measures. Journal of Voice, 7(3), 242-249. doi:http://dx.doi.org/10.1016/S0892-1997(05)80333-9

Rubin, J. S., Blake, E., \& Mathieson, L. (2007). Musculoskeletal Patterns in Patients With Voice Disorders. Journal of Voice, 21(4), 477-484. doi:http://dx.doi.org/10.1016/j.jvoice.2005.02.001

Rubin, J. S., Mathieson, L., \& Blake, E. (2004). Posture and voice. J. Singing, 60(January/February), 271-275.

Rundell, K. W. P. F., \& Weiss, P. M. D. (2013). Exercise-Induced Bronchoconstriction and Vocal Cord Dysfunction: Two Sides of the Same Coin? Current Sports Medicine Reports January/February, 12(1), 45-50.

Ruotsalainen, J., Sellman, J., Lehto, L., \& Verbeek, J. (2008). Systematic review of the treatment of functional dysphonia and prevention of voice disorders. Otolaryngology - Head and Neck Surgery, 138(5), 557565. doi:http://dx.doi.org/10.1016/j.otohns.2008.01.014

Ruotsalainen, J. H., Sellman, J., Lehto, L., Jauhiainen, M., \& Verbeek, J. H. (2007). Interventions for treating functional dysphonia in adults. Cochrane Database of Systematic Reviews, (3) (no pagination)(CD006373). doi:http://dx.doi.org/10.1002/14651858.CD006373.pub2

Røksund, O. D., Heimdal, J.-H., Clemm, H., Vollsæter, M., \& Halvorsen, T. (2016). Exercise inducible laryngeal obstruction: diagnostics and management. Paediatric Respiratory Reviews. Retrieved from http://www.sciencedirect.com/science/article/pii/S152605421630063X

Sandnes, A., Andersen, T., Hilland, M., Ellingsen, T. A., Halvorsen, T., Heimdal, J. H., \& Roksund, O. D. (2013). Laryngeal movements during inspiratory muscle training in healthy subjects. Journal of Voice, 27(4), 448-453. doi:http://dx.doi.org/10.1016/i.jvoice.2013.02.010

Schneider, C. M., Dennehy, C. A., \& Saxon, K. G. (1997). Exercise physiology principles applied to vocal performance: the improvement of postural alignment. J Voice, 11(3), 332-337.

Shipp, T. (1987). Vertical laryngeal position: Research findings and application for singers. Journal of Voice, 1(3), 217-219. doi:http://dx.doi.org/10.1016/S0892-1997(87)80002-4

Staes, F. F., Jansen, L., Vilette, A., Coveliers, Y., Daniels, K., \& Decoster, W. (2011). Physical therapy as a means to optimize posture and voice parameters in student classical singers: a case report. Journal of Voice, 25(3), e91-101. doi:https://dx.doi.org/10.1016/i.jvoice.2009.10.012

Standring, S. (2008). Gray's anatomy - the anatomical basis of clinical practrice (S. Standring Ed. 40 ed.). Spain: Churchill Livingstone \& Elsevier.

Sullivan, M. D., Heywood, B. M., \& Beukelman, D. R. (2001). A Treatment for Vocal Cord Dysfunction in Female Athletes: An Outcome Study. Laryngoscope, 111(10), 1751-1755.

Tervonen, H., Niskanen, M. M., Sovijarvi, A. R., Hakulinen, A. S., Vilkman, E. A., \& Aaltonen, L. M. (2009). Fiberoptic videolaryngoscopy during bicycle ergometry: A diagnostic tool for exercise-induced vocal cord dysfunction. Laryngoscope, 119(9), 1776-1780. doi:http://dx.doi.org/10.1002/lary.20558

Thomas, P. S., Geddes, D. M., \& Barnes, P. J. (1999). Pseudo-steroid resistant asthma. Thorax, 54(4), 352-356.

Tomlinson, C. A., \& Archer, K. R. (2015). Manual therapy and exercise to improve outcomes in patients with muscle tension dysphonia: a case series. Physical Therapy, 95(1), 117-128. doi:http://dx.doi.org/10.2522/ptj.20130547

Van Houtte, E., Van Lierde, K., \& Claeys, S. (2011). Pathophysiology and Treatment of Muscle Tension Dysphonia: A Review of the Current Knowledge. Journal of Voice, 25(2), 202-207. doi:http://doi.org/10.1016/i.jvoice.2009.10.009

Van Lierde, K. M., Bodt, M. D., Dhaeseleer, E., Wuyts, F., \& Claeys, S. (2010). The Treatment of Muscle Tension Dysphonia: A Comparison of Two Treatment Techniques by Means of an Objective 
Multiparameter Approach. Journal of Voice, 24(3), 294-301.

doi:https://doi.org/10.1016/i.jvoice.2008.09.003

Vann, N. C., Pham, F. D., Hayes, J. A., Kottick, A., \& Del Negro, C. A. (2016). Transient suppression of Dbx1 PreBotzinger interneurons disrupts breathing in adult mice. PLOS ONE, 11 (9) (no pagination)(e0162418). doi:http://dx.doi.org/10.1371/journal.pone.0162418

Waersted, M., Bjorklund, R. A., \& Westgaard, R. H. (1994). The effect of motivation on shoulder-muscle tension in attention-demanding tasks. Ergonomics, 37(2), 363-376.

Walsted, E. S., Hull, J. H., Hvedstrup, J., Maat, R. C., \& Backer, V. (2017). Validity and reliability of grade scoring in the diagnosis of exercise-induced laryngeal obstruction. ERJ Open Research, 3(3), 1-9. doi:DOI: 10.1183/23120541.00070-2017

Wilhelm, F. H., Gevirtz, R., \& Roth, W. T. (2001). Respiratory dysregulation in anxiety, functional cardiac, and pain disorders: Assessment, phenomenology, and treatment. Behavior Modification, 25(4), 513-545.

Wilson Arboleda, B. M., \& Frederick, A. L. (2008). Considerations for Maintenance of Postural Alignment for Voice Production. Journal of Voice, 22(1), 90-99. doi:http://dx.doi.org/10.1016/j.jvoice.2006.08.001

Wysocki, J., Kielska, E., Orszulak, P., \& Reymond, J. (2008). Measurements of pre- and postpubertal human larynx: A cadaver study. Surgical and Radiologic Anatomy, 30(3), 191-199.

doi:http://dx.doi.org/10.1007/s00276-008-0307-8 